\title{
A plasma flow vortex in the magnetotail and its related ionospheric signatures
}

\author{
C. L. Tang ${ }^{1,2}$ \\ ${ }^{1}$ Shandong Provincial Key Laboratory of Optical Astronomy and Solar-Terrestrial Environment, School of Space Science and \\ Physics, Shandong University at Weihai, Weihai, Shandong, 264209, China \\ ${ }^{2}$ Sate Key Laboratory of Space Weather, Chinese Academy of Sciences, Beijing 100190, China \\ Correspondence to: C. L. Tang (tcl@sdu.edu.cn)
}

Received: 10 October 2011 - Revised: 17 February 2012 - Accepted: 20 February 2012 - Published: 16 March 2012

\begin{abstract}
We presented a large-scale plasma flow vortex event that occurred on 1 March 2009 observed by Time History of Events and Macroscale Interactions during Substorms (THEMIS) satellites. During the interval, THEMIS satellites were located in the premidnight region between 11 and $16 R_{E}$ downtail. Dawnward-earthward plasma flows were seen initially in the magnetotail, followed by duskwardtailward flows. This suggests that a clockwise plasma flow vortex (seen from above the equatorial plane) was observed on the dawn side of the plasma sheet. Furthermore, high energy $(>1 \mathrm{keV})$ electrons were observed. Auroral images at $427.8 \mathrm{~nm}$ and THEMIS white light all-sky imager (ASI) at Fort Smith showed a discrete auroral patch formed at the poleward of the auroral oval, it then intensified. It extended eastward and equatorward first and followed by westward motion to form the clockwise auroral vortex. The auroral feature corresponded to the ionospheric signatures of the plasma flow vortex in the magnetotail when the Alfvén transit time between the magnetotail and the ionosphere was taken into account. We suggest that the large-scale clockwise plasma flow vortex in association with the high energy $(>1 \mathrm{keV})$ electrons on the dawn side of the plasma sheet generated a downward field-aligned current (FAC) that caused the related ionospheric signatures. The plasma flow vortex had rotational flow speeds of up to $300 \mathrm{~km} \mathrm{~s}^{-1}$. The current density associated with the plasma flow vortex was estimated at $2.0 \mu \mathrm{A} \mathrm{m}^{-2}$, mapped to the ionosphere.
\end{abstract}

Keywords. Magnetospheric physics (Plasma convection)

\section{Introduction}

Vortex-like plasma flow structures are common in the Earth's magnetosphere. They prevail in the nightside plasma sheet (Hones, 1978, 1981, 1983; Keiling et al., 2009) and at the flank magnetospheric low-latitude boundary layers (LLBLs) (Fairfield et al., 2000; Otto and Fairfield, 2000; Hasegawa et al., 2004). Plasma vortex-like flows have also been observed on the middle to high-latitude boundary of the outer radiation belt by the Cluster spacecraft fleet (Zong et al., 2009). The plasma flow vortex found in the magnetotail is characterized by pronounced vortical motion in the plane that is approximately parallel to the ecliptic plane. The period for a vortex with $360^{\circ}$ rotation ranges from 5 to $20 \mathrm{~min}$. Those observed series of vortex-like plasma flows can last for several hours (Hones, 1978). The rotations have a preferred sense, clockwise on the dawn side of the magnetotail and counterclockwise on the dusk side.

Vortex-like plasma flows in the plasma sheet are thought to be important in transportation of the kinetic energy from fast flow or bursty bulk flows (BBFs) in the magnetotail to the near Earth region (Snekvik et al., 2007; Keiling et al., 2009). A sudden braking and/or azimuthal deflection of BBFs may generate the plasma flow vortices at the boundary between the magnetotail plasma sheet and the inner magnetosphere as suggested by Hasegawa (1979) and Vasyliunas (1984). Keika et al. (2009) have shown that plasma vortices are formed near the region where the earthward flows slow down and turn in azimuthal directions. The theoretical relation between the field-aligned current (FAC) and plasma vorticity showed that FACs are generated to transport transverse momentum along magnetic field lines (Pritchett and Coroniti, 2000). Keiling et al. (2009) presented a scenario in which the plasma flow 


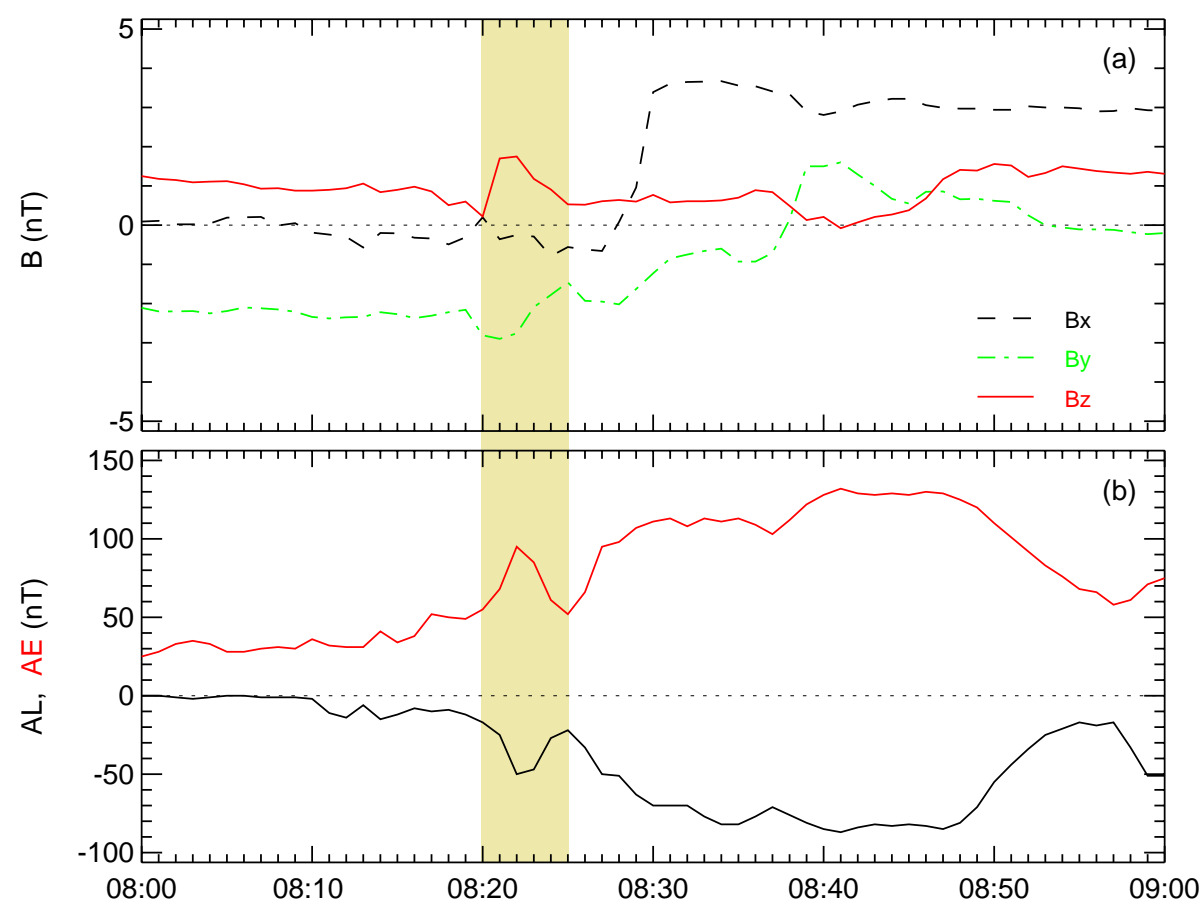

Fig. 1. (a) The IMF components seen by Wind propagated to 1 AU (Details of the applied time shift can be found on the CDA website for the OMNI data source. The averaged time shift for this interval is $\sim 50 \mathrm{~min}$ ), with the interest interval; (b) AL and AE indices.
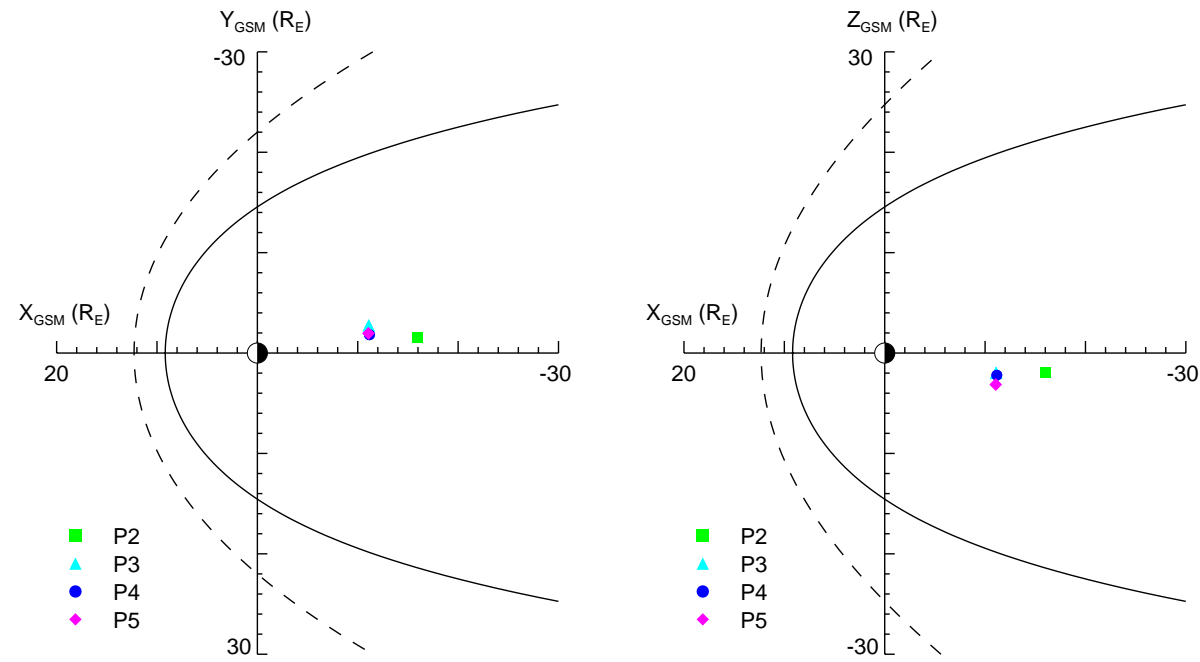

Fig. 2. The locations of four THEMIS satellites (P2, P3, P4 and P5) in the magnetosphere are shown in the GSM X-Y and X-Z planes.

vortices in the plasma sheet generated the FAC of the substorm current wedge (SCW) at the beginning of the substorm expansion phase and coupled to the ionosphere, causing the ionospheric vortices. Based on the auroral images at $630 \mathrm{~nm}$ from all-sky imager (ASI) in Rankin Inlet, Lui et al. (2010) suggested that the plasma flow vortices could be related to an auroral streamer through FACs.

In this paper, we will present a large-scale plasma flow vortex event that occurred on 1 March 2009 using the observations from four Time History of Events and
Macroscale Interactions during Substorms (THEMIS) (Angelopoulos, 2008) satellites. The concurrent observations in the ionosphere were revealed using multi-spectral ASI (Donovan et al., 2003) and the THEMIS white light imager (Mende et al., 2008) data from Fort Smith $\left(67.38^{\circ}\right.$ Geom. Lat. $/ 306.64^{\circ} \mathrm{Geom}$. Lon.). In the present study, the auroral feature was related to the clockwise plasma flow vortex in association with high energy $(>1 \mathrm{keV})$ electrons, distinctly different from the plasma flow vortex (increase in the ratio of the ion energy over the electron energy) observed by Lui 

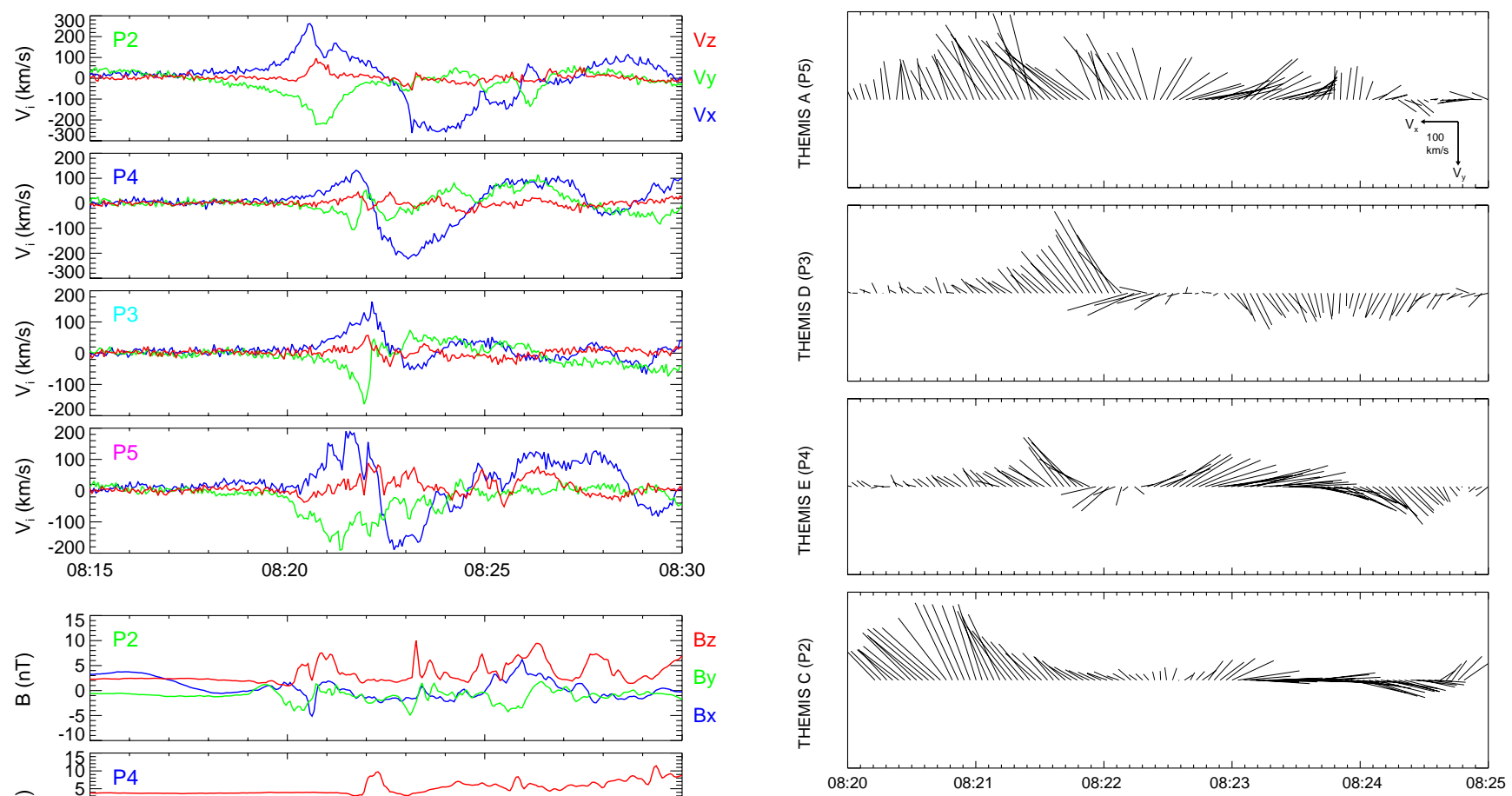

Fig. 4. Vector plots of the flow velocities (projected onto the GSM $\mathrm{X}-\mathrm{Y}$ plane) for four THEMIS satellites (P2, P3, P4, and P5).

$-1.58,-1.96) R_{E}, \mathrm{P} 3$ at $(-11.10,-2.76,-1.95) R_{E}, \mathrm{P} 4$ at $(-11.17,-1.82,-2.21) R_{E}$ and $\mathrm{P} 5$ at $(-11.06,-1.96$, $-3.14) R_{E}$. Therefore, they were grouped in two tail regions with $\mathrm{P} 2$ near $\sim 16 R_{E}$ downtail while the others were near $\sim 11 R_{E}$.

Figure 3 shows data from four THEMIS satellites during the plasma flow vortex event (from top to bottom: P2, P4, P3, and P5). Figure 3 (top) shows $3 \mathrm{~s}$ (spin) resolution GSM components of the ion bulk velocity. Figure 3 (bottom) shows $3 \mathrm{~s}$ (spin) resolution GSM components of the magnetic field measured by the Flux Gate Magnetometer (FGM) instrument (Auster et al., 2008). These velocity components are determined by combining plasma measurements from the electrostatic analyzers (ESA) (McFadden et al., 2008) and energetic particle measurements from the solid-state telescopes (SST) (Angelopoulos, 2008). In Fig. 3 (top), one can see that four satellites (P2, P3, P4 and P5) observed the flow reversals. From Fig. 3 (bottom), the strong magnetic field fluctuations at $\mathrm{P} 2$ were observed, and the similar changes of the magnetic field were observed by P3, P4, and P5. During the tailward flows, a positive $B_{\mathrm{Z}}$ was observed by four THEMIS satellites.

Figures 4 and 5 show the temporal variations of the plasma flows on the X-Y plane (GSM). In Fig. 4, the flow vectors for four THEMIS satellites are plotted versus time. From Fig. 4, a plasma flow vortex occurred in the magnetotail. Figure 5 further illustrated the time sequence of the plasma flow vortex. The first four snapshots in Fig. 5, between 08:20:20 and 


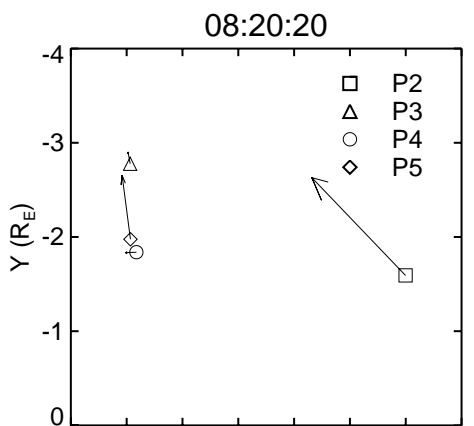

$08: 21: 50$

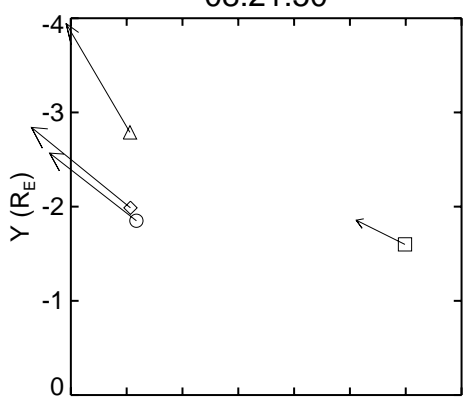

08:23:20

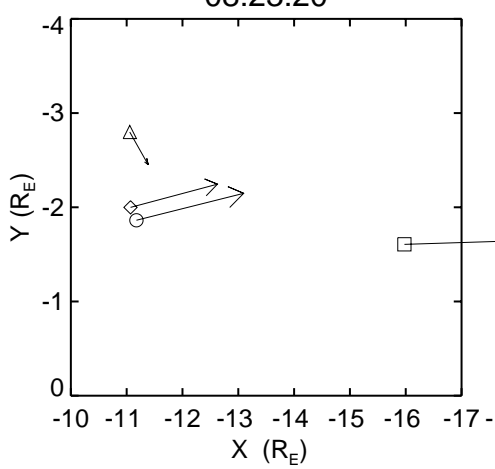

08:20:50

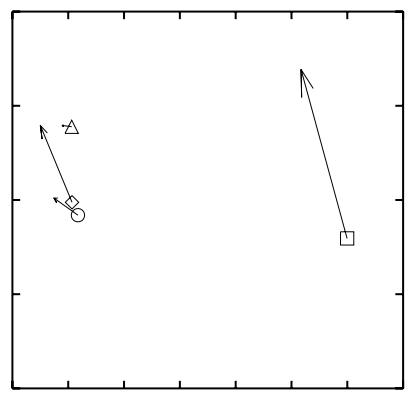

08:22:20

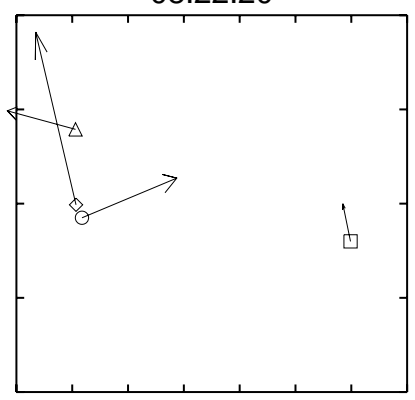

08:23:50

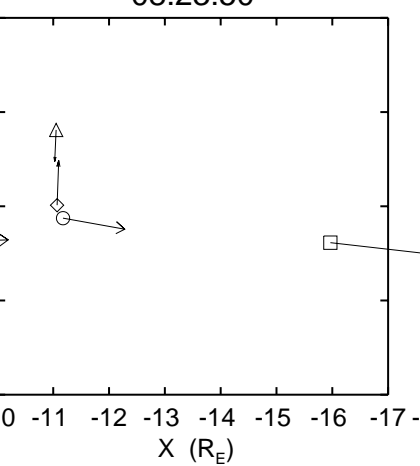

08:21:20

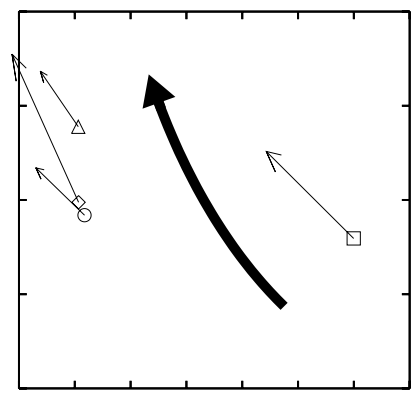

08:22:50

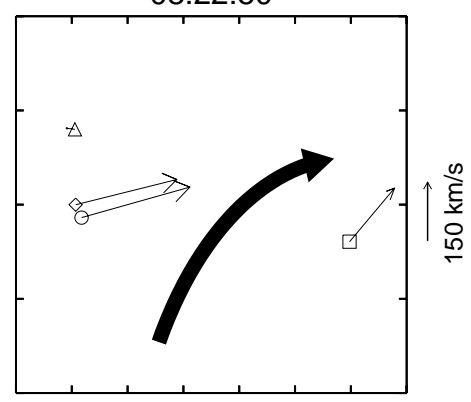

08:24:20

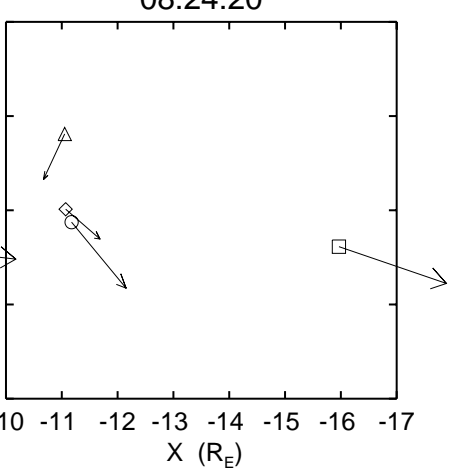

Fig. 5. THEMIS satellites (P2, P3, P4, and P5) positions overlaid with flow vectors.

08:21:50 UT, showed that the plasma flows were eastward and dawnward. At 08:22:20 UT, the flows at P4 rotated to have a tailward component. The following two snapshots (08:22:50-08:23:20 UT) showed that the plasma flows rotated further in the tailward direction. Finally, at 08:24:20 UT the plasma flows appeared to move tailward and duskward, as detected by P2, P4 and P5. From Fig. 5, a clockwise plasma flow vortex (seen from above the equatorial plane) was observed on dawn side of the plasma sheet.

Images from the all-sky multi-spectral imager $(630.0 \mathrm{~nm}$ and $427.8 \mathrm{~nm}$ ) and the THEMIS white light imager at Fort Smith are shown in Fig. 6. The four columns represent data from two wavelengths, $\lambda=630.0 \mathrm{~nm}, 427.8 \mathrm{~nm}$, and white light (two columns). The different auroral wavelengths respond to different energy ranges of electron precipitation. The $\lambda=630.0 \mathrm{~nm}$ band is sensitive to low energy $(<1 \mathrm{keV})$ electrons (Rees and Roble, 1986), which also makes the $630.0 \mathrm{~nm}$ emission observable at higher latitudes where the incident electron population is less energetic than at lower latitudes. The $\lambda=427.8 \mathrm{~nm}$ emission $\left(\mathrm{N}_{2}^{+}\right)$is correlated with the energy of the precipitating electrons, and an increase in brightness often indicates an increase in precipitating electron energy (Eather and Mende, 1971).

Starting near 08:24:04 UT, an auroral patch was observed in the $\lambda=427.8 \mathrm{~nm}$ wavelength images (marked with a red arrow). The image at 08:24:04 UT showed a clear gap between the patch and the auroral oval. At 08:25:04 UT, the equatorward edge of the patch merged into the auroral oval. The white light images showed the same structure. The auroral patch first occurred at 08:23:40 UT, and it then intensified. At 08:24:20 UT, it developed a significant eastward and equatorward extension. Subsequently, the auroral patch moved westwards and formed the clockwise auroral vortex at 08:24:50 UT. The $\lambda=630.0 \mathrm{~nm}$ images did not show the active auroral feature. 


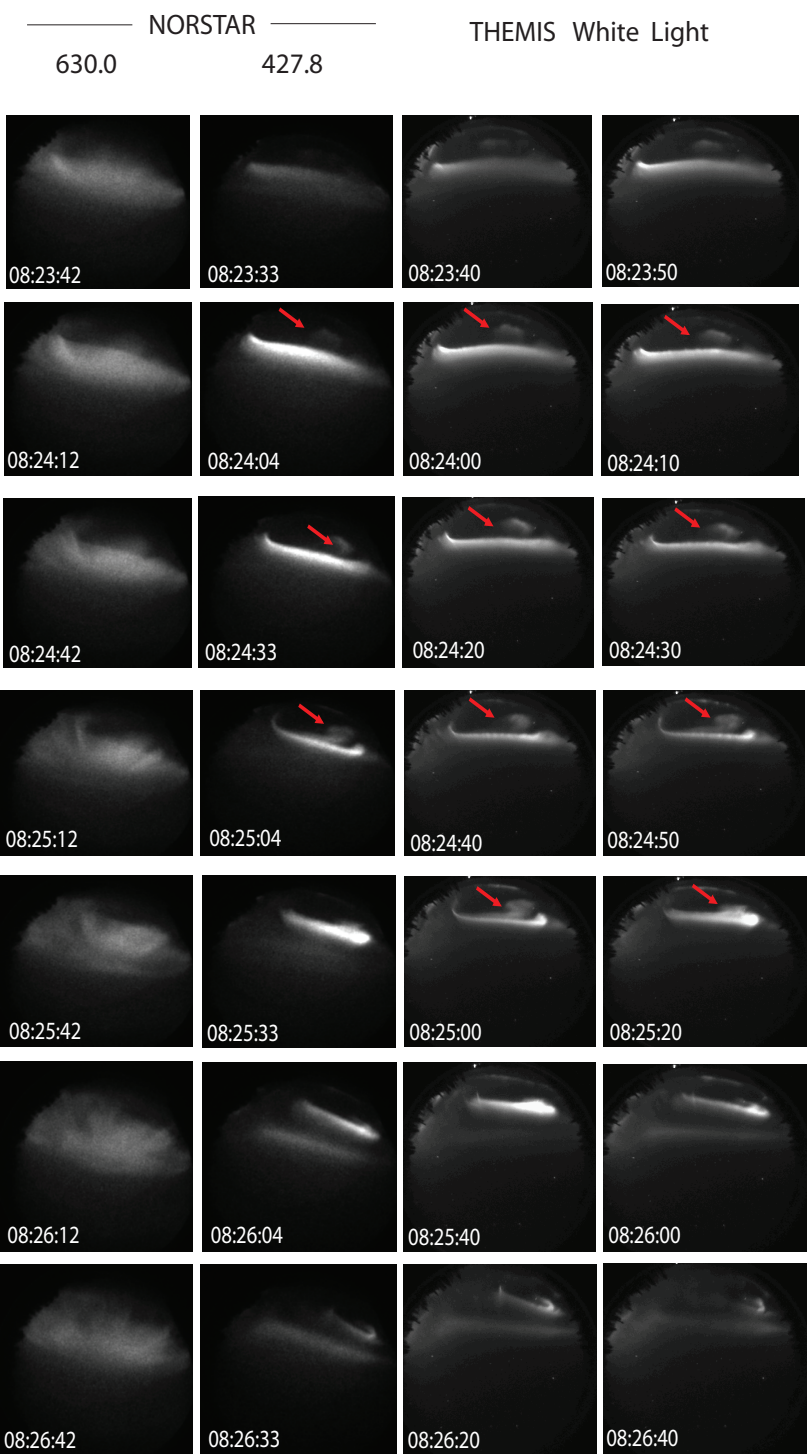

Fig. 6. The time sequence of the raw auroral images from the multispectral $(630.0 \mathrm{~nm}$ and $427.8 \mathrm{~nm})$ and THEMIS white light ASI at Fort Smith on 1 March 2009 showing the formation of an auroral vortex when THEMIS satellites were in the same local time sector.

To show clearly the auroral activity, it is better to project the raw white light images onto a geographic grid (Fig. 7). The ionospheric footprints of THEMIS satellites (P2, P3, P4, and P5) mapped along field lines using the T01 model (Tsyganenko, 2002) are near the station of Fort Smith. At 08:23:30 UT, a discrete auroral patch formed at the poleward of the auroral oval, and it then intensified. At 08:24:42 UT, it developed a significant eastward extension and the equatorward edge of the patch merged into the auroral oval. At the same time, the aurora patch rapidly expanded westward and poleward. At 08:25:06 UT, the aurora patch continued to expand azimuthally and poleward. Simultaneously, the clockwise auroral vortex formed. After 08:26:18 UT, the westward aurora began to weak, but the eastward moving streamer was observed.

\section{Discussion and summary}

Based on the auroral images from $630.0 \mathrm{~nm}$ ASI at Rankin Inlet, Lui et al. (2010) showed that the process generating the auroral feature of a vortex pattern is related to the flow vortex, in association with the depletion of the electron energy relative to the ion energy and wave-particle interaction. Rees and Roble (1986) showed that an incident Maxwellian electron spectrum with a characteristic energy of $0.1 \mathrm{keV}$ and total energy-input rate of $1 \mathrm{erg} \mathrm{s}^{-1} \mathrm{~cm}^{-2}$ can produce a significant emission in the $\lambda=630.0 \mathrm{~nm}$ band. Additionally, the $630.0 \mathrm{~nm}$ emission is a high altitude emission (typically taken to be $230 \mathrm{~km}$ (Sharp et al., 1979)). The $630.0 \mathrm{~nm}$ emissions at Fort Smith did not show the clear auroral feature in the present event. The $427.8 \mathrm{~nm}$ emissions exhibited a different behavior. The $427.8 \mathrm{~nm}$ emissions are generated by higher energy electrons, and more typically associate with discrete auroral arcs as opposed to scattered plasma sheet particles (Kepko et al., 2009). The images shown in Fig. 7 indicate that the discrete auroral patch first occurred, and it then intensified. Subsequently, the auroral patch extended eastward and equatorward, followed by westward motion to form the clockwise auroral vortex. In relating the plasma flow vortex in the magnetotail with the auroral feature, one must take into account the Alfvén transit time delay between the magnetotail to the ionosphere, which was about $\sim 2-3$ min for the tail distances of the THEMIS satellites. The first clear enhancement of plasma flow at P2 was at $\sim 08: 20: 20$ UT (see Fig. 5). With the transit time delay, this activity would correspond to the auroral activity at $\sim 08: 23: 30$ UT (the discrete auroral patch occurred). As the plasma flows in the midtail transport toward the near Earth region, the eastward and equatorward moving auroral patch was observed (see Fig. 7, $\sim 08: 23: 54$ and 08:24:18 UT). The sudden braking and/or azimuthal deflection of the plasma flows may generate the plasma flow vortices between the mid-tail and the inner magnetosphere (see Fig. 5, 08:22:50 UT). This may be related to the vortex pattern of the auroral feature at 08:25:06 UT (see Fig. 7). The aurora patch with the eastward motion first,followed by the westward motion is related to the development of the flow pattern in the magnetotail observed by four THEMIS satellites (see Fig. 5, the 08:21:20 and 08:22:50 UT panels). During the interval, the high energy $(>1 \mathrm{keV})$ electrons were observed by P5 (Fig. 8). Furthermore, the high energy ( $>1 \mathrm{keV})$ electrons were correlated with the auroral intensification. These correlations suggest that P5 was conjugate to individual structures during the auroral activity. The combined ground and space observations suggest that the large-scale clockwise plasma flow vortex in association with the high energy $(>1 \mathrm{keV})$ electrons on the dawn side of the plasma sheet generated the downward 

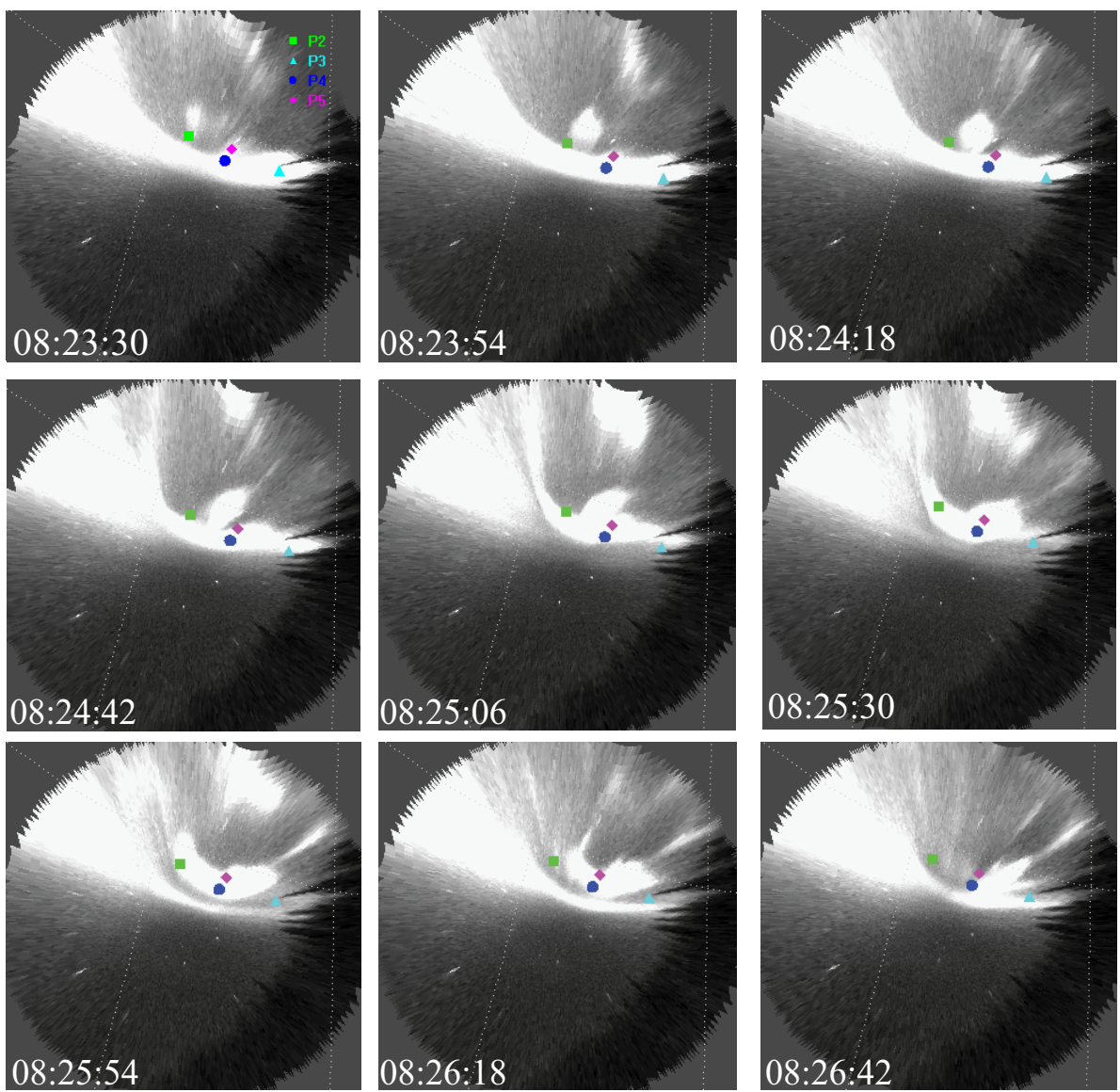

Fig. 7. A sequence of THEMIS ASI images showing the formation of an auroral vortex at Fort Smith on 1 March 2009. The positions of P2, P3, P4, and P5 are marked with a green filled square, a cyan filled upward triangle, a blue filled circle and a magenta filled diamond, mapped as described in the text, respectively.

FAC and coupled to the ionosphere, causing the related ionospheric signatures. Kepko et al. (2009) have shown that a small arc (427.8 $\mathrm{nm}$ emissions) slanted slightly relative to the equatorward boundary may also be related to increased flow diversion and magnetic shear ahead of the flow as it nears the inner magnetosphere, leading to strong FACs (e.g. Birn and Hesse, 1996). There were some noticeable earthward flows in the magnetotail from 08:25 to 08:30 UT, which led to the eastward moving streamer.

Between 08:20 and 08:25 UT, the flow pattern revealed a large-scale plasma flow vortex in the transition region between the mid-tail and the near-Earth region observed by four THEMIS satellites. The duration of the plasma flow vortex was about 3 min and gradually faded away. The width of the flow vortex in the north-south direction may be smaller than the flow channel (Nakamura et al., 2004), with a diameter of at least $5 R_{E}$. The scale of this plasma flow vortex was in agreement with global MHD modeling estimates (Birn et al., 1999, 2004; El-Alaoui, 2001; El-Alaoui et al., 2009; Ugai, 2009a, b; Panov et al., 2010) and much larger than the estimates of Keika et al. (2009) and Keiling et al. (2009). The clockwise flow vortex on the dawn side of the plasma sheet, which generated a downward FAC, caused the corresponding ionospheric signatures (the discrete auroral patch extended eastward and equatorward first and followed by westward motion to form the clockwise auroral vortex). This sense is the same as that discussed by Birn et al. (2004) and Keiling et al. (2009). If one assumes that the downward FAC has a similar strength as the vortex current density, it can be estimated through the temporal change of vorticity. With the FAC formula given by Hasegawa and Sato (1979) and the procedure by Lui (1996), one obtains

$j_{\|} \approx \frac{L_{\mathrm{z}}}{L_{\mathrm{v}}} \frac{1}{\omega_{\mathrm{i}} \tau} \frac{B_{\mathrm{i}}}{B_{\mathrm{m}}} j_{\mathrm{y}}$

where $j_{\|}$is the FAC in the ionosphere, $L_{\mathrm{Z}}$ is the plasma sheet thickness in the z-direction, $L_{\mathrm{V}}$ is the length scale of the flow vorticity, $\omega_{\mathrm{i}}$ is the ion gyrofrequency, $\tau$ is the time scale of vorticity change, $B_{\mathrm{i}}$ is the magnetic field at the ionosphere, $B_{\mathrm{m}}$ is the magnetic field in the magnetosphere, and $j_{\mathrm{y}}$ is the cross-tail current density averaged in the z-direction (Lui et al., 2010). If we take $L_{\mathrm{z}} \approx 0.1 L_{\mathrm{v}}, B_{\mathrm{m}}=10 \mathrm{nT}$, 
P5 (THEMIS A)
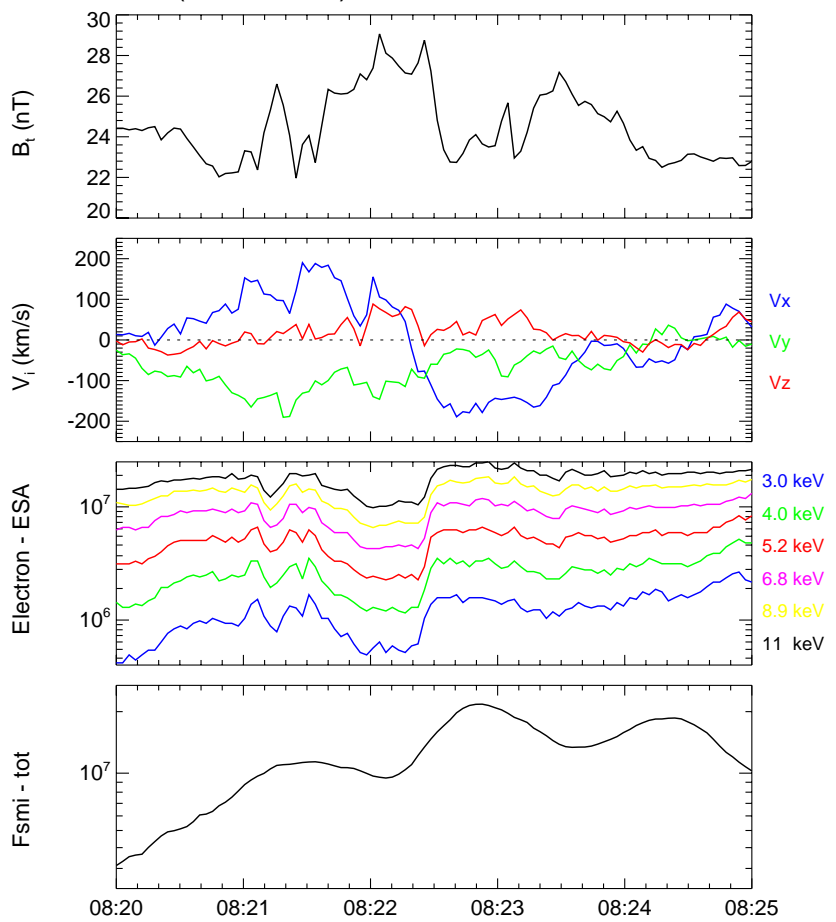

Fig. 8. The observations of the magnetic field strength $B_{\mathrm{t}}$, the plasma flow $V_{\mathrm{i}}$, and electron injection data $(3-11 \mathrm{KeV})$ recorded by $\mathrm{P} 5$ and the integrated brightness (image totals) of all-sky images at Fort Smith (the Alfvén transit time between the magnetotail and the ionosphere is taken into account) during the plasma flow vortex interval.

$B_{\mathrm{i}}=60000 \mathrm{nT}, \tau=30 \mathrm{~s}, j_{\mathrm{y}}=3 \mathrm{nAm}^{-2}, \omega_{\mathrm{i}}$ based on $B_{\mathrm{m}}$, then $j_{\|} \approx 2.4 \mu \mathrm{A} \mathrm{m}^{-2}$. The estimated current density for the auroral feature is high, consistent with the high intensity of the observed auroral feature.

Another method to estimate the FAC in the ionosphere is the approximate expression of Sato and Iijima (1979) by assuming the uniform, incompressible plasma and a solid-body rotation for the vortex as done by Keiling et al. (2009) and Lui et al. (2010):

$j_{\|} \approx 2 \frac{L_{\mathrm{z}}}{L_{\mathrm{v}}} \frac{\rho v}{B_{\mathrm{m}} \tau} \frac{B_{\mathrm{i}}}{B_{\mathrm{m}}}$

where $\rho$ is the mass density and $v$ is the initial total plasma flow for the vortex. Taking the $\rho \sim 1.67 \times 10^{-27} \mathrm{~kg} \mathrm{~cm}^{-3}$ and $v \sim 300 \mathrm{~km} \mathrm{~s}^{-1}$, we get $j_{\|} \approx 2.0 \mu \mathrm{A} \mathrm{m}^{-2}$, which is quite comparable with the first estimate. However, the downward FAC in the present event is smaller than the FAC of SCW driven by plasma flow vortices observed by Keiling et al. (2009).

Acknowledgements. This work is supported by the National Natural Science Foundation of China grants 41004075, 40825014, and 40890162. This work is also supported in part by the Shandong Province Natural Science Foundation of grants ZR2010DQ014. The project was supported by the Specialized Research Fund for
State Key Laboratories by the Open Research Fund in China and the Open Research Fund for SOA Key Laboratory for Polar Science in China (KP201105). We thank J. Liang for the use of the allsky multi-spectral images, CDAWeb for wind data, WDC-C2 for AU/AL indices, V. Angelopoulos for THEMIS mission, J. P. McFadden for ESA data, D. Larson for SST data, and K.-H. Glassmeier for FGM data. We thank V. Angelopoulos for the useful discussion in evaluating this paper.

Topical Editor R. Nakamura thanks A. Lui and Z. Pu for their help in evaluating this paper.

\section{References}

Angelopoulos, V.: The THEMIS Mission, Space Sci. Rev., 141, 453-476, doi:10.1007/s11214-008-9336-1, 2008.

Auster, H. U., Glassmeier, K. H., Magnes, W., Aydogar, O., Baumjohann, W., Constantinescu, D., Fischer, D., Fornacon, K. H., Georgescu, E., Harvey, P., Hillenmaier, O., Kroth, R., Ludlam, M., Narita, Y., Nakamura, R., Okrafka, K., Plaschke, F., Richter, I., Schwarzl, H., Stoll, B., Valavanoglou, A., and Wiedemann, M.: The THEMIS fluxgate magnetometer, Space Sci. Rev., 141, 235-264, doi:10.1007/s11214-008-9365-9, 2008.

Birn, J. and Hesse, M.: Details of current disruption and diversion in simulations of magnetotail dynamics, J. Geophys. Res., 101, 15345-15358, 1996.

Birn, J., Hesse, M., Haerendel, G., Baumjohann, W., and Shiokawa, K.: Flow braking and the substorm current wedge, J. Geophys. Res., 104, 19895-19904, doi:10.1029/1999JA900173, 1999.

Birn, J., Raeder, J., Wang, Y. L., Wolf, R. A., and Hesse, M.: On the propagation of bubbles in the geomagnetic tail, Ann. Geophys., 22, 1773-1786, doi:10.5194/angeo-22-1773-2004, 2004.

Donovan, E., Trondsen, T., Cogger, L., and Brian, J.: Auroral imaging in Canadian CANOPUS and NORSTAR programs, paper presented at the 30th Annual European Meeting on Atmospheric Studies by Optical Methods, Univ. Courses on Svalbard, Longyearbyen, Norway, 2003.

Eather, R. H. and Mende, S. B.: Airborne observations of auroral precipitation patterns, J. Geophys. Res., 76, 1746-1755, 1971.

El-Alaoui, M.: Current disruption during November 24, 1996, substorm, J. Geophys. Res., 106, 6229-6246, doi:10.1029/1999JA000260, 2001.

El-Alaoui, M., Ashour-Abdalla, M., Walker, R. J., Peroomian, V., Richard, R. L., Angelopoulos, V., and Runov, A.: Substorm evolution as revealed by THEMIS satellites and a global MHD simulation, J. Geophys. Res., 114, A08221, doi:10.1029/2009JA014133, 2009.

Fairfield, D. H., Otto, A., Mukai, T., Kokubun, S., Lepping, R. P., Steinberg, J. T., Lazarus, A. J., and Yamamoto, T.: Geotail observations of the kelvin-helmholtz instability at the equatorial magnetotail boundary for parallel northward fields, J. Geophys. Res., 105, 21159-21173, 2000.

Hasegawa, A. and Sato, T.: Generation of field aligned current during substorm, in: Dynamics of the Magnetosphere, edited by: Akasofu, S. I. and Reidel, D., Dordrecht, Netherlands, 529-542, 1979.

Hasegawa, H., Fujimoto, M., Phan, T. D., Reme, H., Balogh, A., Dunlop, M. W., Hashimoto, C., and TanDokoro, R.: Transport of solar wind into Earth's magnetosphere through rolled-up KelvinHelmholtz vortices, Nature, 430, 755-758, 2004. 
Hones, E. W.: Vortices in magnetospheric plasma flow, Geophys. Res. Lett., 5, 1059-1062, 1978.

Hones, E. W.: Further determination of the characteristics of magnetospheric plasma vortices with ISEE 1 and 2, J. Geophys. Res., 86, 814-819, 1981.

Hones, E. W.: New observations of plasma vortices and insights into their interpretation, Geophys. Res. Lett., 10, 674-677, 1983.

Keika, K., Nakamura, R., Volwerk, M., Angelopoulos, V., Baumjohann, W., Retinò, A., Fujimoto, M., Bonnell, J. W., Singer, H. J., Auster, H. U., McFadden, J. P., Larson, D., and Mann, I.: Observations of plasma vortices in the vicinity of flow-braking: a case study, Ann. Geophys., 27, 3009-3017, doi:10.5194/angeo27-3009-2009, 2009.

Keiling, A., Angelopoulos, V., Runov, A., Weygand, J., Apatenkov, S. V., Mende, S., McFadden, J., Larson, D., Amm, O., Glassmeier, K.-H., and Auster, H. U.: Substorm current wedge driven by plasma flow vortices: THEMIS observations, J. Geophys. Res., 114, A00C22, doi:10.1029/2009JA014114, 2009.

Kepko, L., Spanswick, E., Angelopoulos, V., Donovan, E., McFadden, J., Glassmeier, K.-H., Raeder, J., and Singer, H. J.: Equatorward moving auroral signatures of a flow burst observed prior to auroral onset, Geophys. Res. Lett., 36, L24104, doi:10.1029/2009GL041476, 2009.

Lui, A. T. Y.: Current disruption in the Earth's magnetosphere: Observations and models, J. Geophys. Res., 101, 13067-13088, doi:10.1029/96JA00079, 1996.

Lui, A. T. Y., Spanswick, E., Donovan, E. F., Liang, J., Liu, W. W., LeContel, O., and Zong, Q.-G.: A transient narrow poleward extrusion from the diffuse aurora and the concurrent magnetotail activity, J. Geophys. Res., 115, A10210, doi:10.1029/2010JA015449, 2010.

McFadden, J. P., Carlson, C. W., Larson, D., Angelopoulos, V., Ludlam, M., Abiad, R., and Elliot, B.: The THEMIS ESA plasma instrument and inflight calibration, Space Sci. Rev., 141, 277-302, doi:10.1107/s11214-008-9440-2, 2008.

Mende, S. B., Harris, S. E., Frey, H. U., Angelopoulos, V., Russell, C. T., Donovan, E., Jackel, B., Greffen, M., and Peticolas, L. M.: The THEMIS array of ground based observatories for the study of auroral substorms, Space Sci. Rev., 141, 357-387, doi:10.1007/s11214-008-9380-x, 2008.

Nakamura, R., Baumjohann, W., Mouikis, C., Kistler, L. M., Runov, A., Volwerk, M., Asano, Y., Voros, Z., Zhang, T. L., Klecker, B., Reme, H., and Balogh, A.: Spatial scale of high-speed flows in the plasma sheet observed by Cluster, Geophys. Res. Lett., 31, L09804, doi:10.1029/2004GL019558, 2004.
Otto, A. and Fairfield, D. H.: Kelvin-Helmholtz instability at the magnetotail boundary: MHD simulation and comparison with Geotail observations, J. Geophys. Res., 105, 21175-21190, 2000.

Panov, E. V., Nakamura,R., Baumjohann, W., Sergeev, V. A., Petrukovich, A. A., Angelopoulos, V., Volwerk, M., Retino, A., Takada, T., Glassmeier, K.-H., McFadden, J. P., and Larson, D.: Plasma sheet thickness during a bursty bulk flow reversal, J. Geophys. Res., 115, A05213, doi:10.1029/2009JA014743, 2010.

Pritchett, P. L. and Coroniti, F.: Localized convection flows and field-aligned current generation in a kinetic model of the nearEarth plasma sheet, Geophys. Res. Lett., 27, 3161-3164, 2000.

Rees, M. H. and Roble, R. G.: Excitation of the $\mathrm{O}\left({ }^{1} \mathrm{D}\right)$ atoms in aurorae and emission of the [oi] 6300-å line, Can. J. Phys., 64, 1608-1613, 1986.

Sato, T. and Iijima, T.: Primary sources of large-scale Birkeland currents, Space Sci. Rev., 24, 347-366, doi:10.1007/BF00212423, 1979.

Sharp, W. E., Rees, M. H., and Stewart, A. I.: Coordinated rocket and satellite measurements of an auroral event: 2 . Rocket observations and analysis, J. Geophys. Res., 84, 1977-1985, 1979.

Snekvik, K., Haaland, S., Østgaard, N., Hasegawa, H., Nakamura, R., Takada, T., Juusola, L., Amm, O., Pitout, F., Rme, H., Klecker, B., and Lucek, E. A.: Cluster observations of a field aligned current at the dawn flank of a bursty bulk flow, Ann. Geophys., 25, 1405-1415, doi:10.5194/angeo-25-1405-2007, 2007.

Tsyganenko, N. A.: A model of the near magnetosphere with a dawn-dusk asymmetry 2. Parameterization and fitting to observations, J. Geophys. Res., 107, 1176, doi:10.1029/2001JA000220, 2002.

Ugai, M.: Fast reconnection evolution in an arcadelike magnetic loop structure, Phys. Plasmas., 16, 062312, doi:10.1063/1.3158949, 2009a.

Ugai, M.: Impulsive magnetic pulsations and electrojets in the loop footpoint driven by the fast reconnection jet, Phys. Plasmas., 16, 112902, doi:10.1063/1.3267869, 2009 b.

Vasyliunas, V. M.: Fundaments of current description, in: Magnetospheric Currents, Geophys Monogr Ser, 28, edited by: Potemra, T. A., AGU, Washington, D.C., 63-66, 1984.

Zong, Q. G., Wang, Y. F., Yang, B., Zhang, H., Tian, A. M., Dunlop, M., Fritz, T. A., Kistler, L. M., Korth, A., Daly, P. W., and Pedersen, A.: Vortex-like plasma flow structures observed by Cluster at the boundary of the outer radiation belt and ring current: A link between the inner and outer magnetosphere, J. Geophys. Res., 114, A10211, doi:10.1029/2009JA014388, 2009. 